\title{
Oral Allergy Syndrome (OAS). General and stomatological aspects
}

\author{
Martina Ausucua, Igone Dublin, Maria A. Echebarria, Jose M. Aguirre
}

Oral Medicine. Stomatology Department. School of Medicine and Odontology. Universidad del País Vasco / EHU

Correspondence:

Medicina Bucal. Departamento de Estomatología

Facultad de Medicina y Odontología

Universidad del Pais Vasco / EHU

Barrio Sarriena $s / n$

Leioa 48940. Vizcaya. Spain

josemanuel.aguirre@ehu.es

\author{
Ausucua M, Dublin I, Echebarria MA, Aguirre JM. Oral Allergy Syn- \\ drome (OAS). General and stomatological aspects. Med Oral Patol Oral \\ Cir Bucal. 2009 Nov 1;14 (11):e568-72 \\ http://www.medicinaoral.com/medoralfree01/v14i11/medoralv14i11p568.pdf

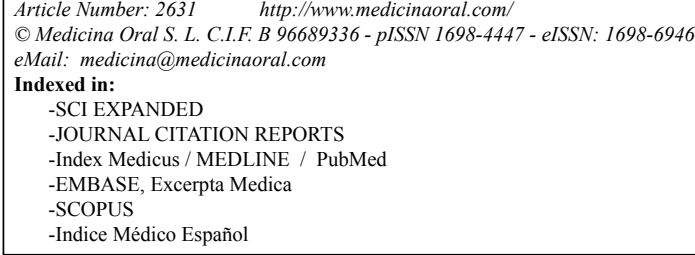

\begin{abstract}
Oral Allergy Syndrome (OAS) is a special contact allergy conditioned by specific amino acids in food allergens, usually fruits, as well as some proteins from different pollens. It is usually manifested in the mouth, however relatively little is known about the syndrome in Odontology. OAS is a fairly common adverse reaction that occurs after ingesting certain foods, such as peaches or apples, produced in atopic individuals who usually suffer from rhinitis, bronchial asthma or both. This syndrome mainly affects the oral cavity and oropharynx, provoking minor local alterations, although there may be serious systematic reactions, making it important to distinguish it from other oral processes when making the diagnosis. One of the more severe forms of OAS is anaphylaxis, which is food-induced. In this study, we will analyze the key etiopathogenic, clinical and therapeutic aspects of this syndrome, focusing specifically on the stomatological aspects.
\end{abstract}

Key words: Oral allergy syndrome, food allergy, cross reactivity, panallergens, oral cavity.

\section{Introduction}

We know that certain sensitivities to certain IgE-mediated air-born allergens are clearly associated to hypersensitivity to certain foods, commonly known as "allergies."

"Oral Allergy Syndrome" (OAS) is induced by the oral and pharynx mucosa's exposure to certain food allergies in hypersensitive patients $(1,2)$. Even though it usually results from an allergic reaction crossed with pollen, it should not be considered an exclusive association between eating specific fruits and vegetables in patients with pollinosis, since in theory any food could induce it (3).

The first description of OAS that associated a hypersen- sitivity to fruits and vegetables to birch pollinosis was written in 1942 by Tuft and Blumstein (4). However, it was not until 1987 when Amlot et al. (5) first denominated it as "Oral Allergy Syndrome" upon presenting a mainly oral clinical manifestation.

Here we will analyse the key etiopathogenic, clinical and therapeutic parameters of this syndrome, with special emphasis on clinically pathological stomatological aspects.

\section{Epidemiology}

There is no authoritative data on the real prevalence of OAS, since the crossed-reactivity patterns show geographical and climatic differences depending on the 
exposure to inhaled and ingested allergens. In central and northern Europe, allergies to fruits in the rosaceae family are closely associated to birch tree pollinosis, even though it is also associated to grass or ragweed pollen (North America) or wormwood (Europe) or cedar (Japan) (6).

Twenty-six to $40 \%$ of adults with pollen allergies (birch, grass and wormwood) present OAS; with the opposite occurring with patients with rosaceae fruit allergies (7, $8)$. A study carried out in Spain (9) notes that more than $80 \%$ of people allergic to peaches are allergic to pollen.

For the majority of patients, OAS is usually always preceded by hay fever and tends to occur more often in children and adults. Some studies (10) have noted that it is more frequent in females.

\section{Etiopathogenic aspects}

In food allergies, we must distinguish between an " $a d$ verse reaction to food" which would be an abnormal clinical response attributed to the ingestion, contact or inhalation of food or additive; and a "food allergy," which is a hypersensitive reaction mediated or not by $\mathrm{IgE}$ antibodies, resulting from ingesting, contact or inhalation of a food or additive (11).

IgE-mediated allergies may be expressed via an immediate gastrointestinal hyper-sensitivity that encompass- es anaphylaxis and immediate enteropathy, or as an oral allergy syndrome (OAS).

OAS is a type II, IgE-mediated allergic reaction that implicates fruits and vegetables and whose immunological base is the development of specific IgE antibodies against proteins. These proteins fulfil basic functions in vegetables, so are widespread and highly preserved in the vegetable kingdom, converting them into "panallergens" responsible for immunological reactivity amongst vegetables and the allergic associations to different pollens and even latex (12). The base of OAS is the existence of $\operatorname{IgE}$ anti-bodies that jointly recognise specific pollen and fruit allergens, rarely manifested in patients without a previous sensitivity to pollen (3). The sensitivity to food allergies may also occur in newborns via the placenta or inhalation in genetically predisposed adults.

In Figure 1 we present a diagram of the key steps of this immunological reaction. The foods associated with OAS and related to different types of pollen appear on Table 1.

Vegetable panallergens are implicated in the vegetables defence mechanism when confronting plagues and pathogens because of their antifungal and anti-parasitic or antibacterial properties, or they may be reserve proteins accumulated in its seeds. The most common are the allergens with Bet $v$ 1, profilins and lipid transport proteins (LTP) $(8,13)$.

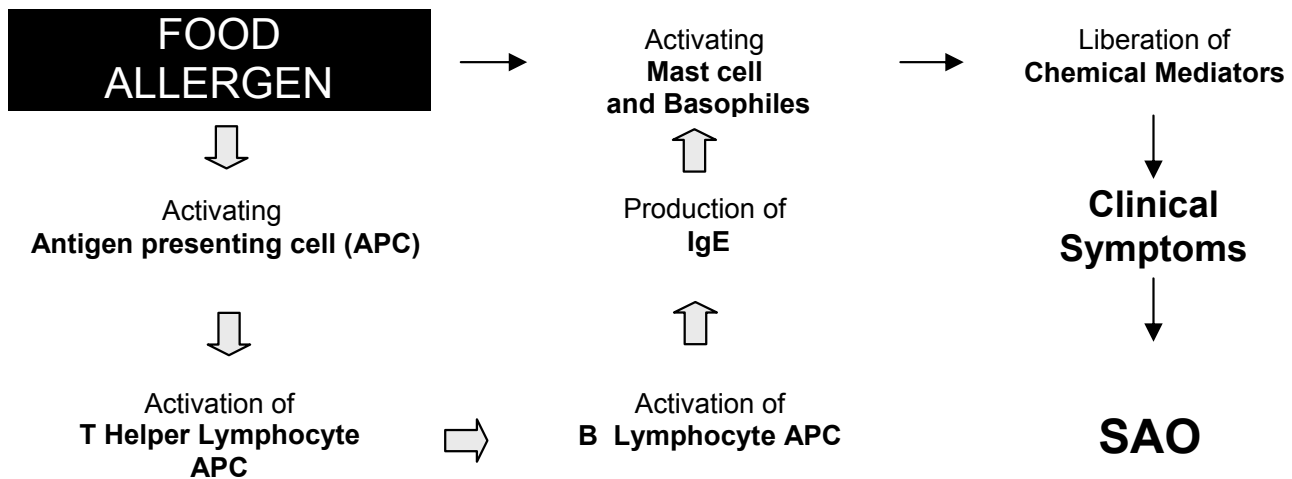

Sensitisation

$\longrightarrow$ Allergic response

Fig. 1. Diagram of the cellular response in the sensitisation and allergic reaction with food allergens. 
Table 1. Types of food and pollen associated to OAS (2).

\begin{tabular}{|c|c|c|c|c|c|c|}
\hline POLLEN & \multicolumn{2}{|c|}{ FRUIT } & \multicolumn{2}{|c|}{ VEGETABLE } & \multicolumn{2}{|c|}{ NUTS } \\
\hline $\mathrm{BIRCH}$ & $\begin{array}{l}\text { Kiwi } \\
\text { Apple } \\
\text { Pear } \\
\text { Plum }\end{array}$ & $\begin{array}{c}\text { Peach } \\
\text { Nectarine } \\
\text { Apricot } \\
\text { Cherry }\end{array}$ & $\begin{array}{c}\text { Celery } \\
\text { Carrot } \\
\text { Parsnip } \\
\text { Parsley } \\
\text { Dill } \\
\text { Cumin } \\
\text { Cilantro } \\
\text { Fennel }\end{array}$ & $\begin{array}{l}\text { Potato } \\
\text { Tomato } \\
\text { Pepper } \\
\text { (green) } \\
\text { Lentils } \\
\text { Peas } \\
\text { Beans } \\
\text { Peanuts }\end{array}$ & $\begin{array}{l}\text { Hazelnut } \\
\text { Walnut }\end{array}$ & Almond \\
\hline RAGWEED & $\begin{array}{c}\text { Banana } \\
\text { Watermelon }\end{array}$ & $\begin{array}{l}\text { Honey } \\
\text { Dew }\end{array}$ & Squash & Cucumber & & \\
\hline WEEDS & $\begin{array}{c}\text { Melon } \\
\text { Watermelon } \\
\text { Tomato }\end{array}$ & $\begin{array}{l}\text { Orange } \\
\text { Kiwi }\end{array}$ & & & & \\
\hline WORMWOOD & $\begin{array}{c}\text { Apple } \\
\text { Watermelon }\end{array}$ & Melon & Celery & Carrot & & \\
\hline PARIETARIA & Cherry & Melon & & & & \\
\hline
\end{tabular}

The Bet $v 1$ family is a group of defence proteins that behave like major allergens in patients in Northern and Central Europe, with vegetable allergies in combination with birch tree pollinosis. These are labile proteins, easy degradable by digestive enzymes and commonly associated to local and minor symptoms. Profilins are proteins highly conserved in eukaryotic organisms that are probably implicated in the transmission of signals and the organisation of the cytoskeleton. For vegetable allergies in patients allergic to birch tree pollen in Northern and Central Europe, profilin behaves like a minor allergen, even though the allergy to rosaceaes combined with pollinosis (gramineaes) in patients in Spain is a serious allergy (14).

Lipid transport proteins (LTP) are major allergens implicated in rosaceaes fruit allergies in patients around the Mediterranean not used to birch tree pollen (15). These proteins are highly resistant to digestive enzymes and thermal treatments, which explains what maintains their allergenic activity in drinks and processed foods (juice, beer). They may be associated to severe systemic symptoms and may provoke hypersensitivity in nonpollinosis patients (16).

\section{Clinical aspects}

The allergic reaction in OAS normally occurs immediately and may occur as soon as the fruit or vegetable is in contact with the oral mucosa. The symptoms often start after a few minutes (maximum one hour), affecting almost exclusively the anatomical regions that enter in contact with the food, generally the oropharynx.

Overall, it is under control quickly and is not usually severe. However, there are cases that it may come accompanied by more severe local and even systemic symptoms.

The oropharynx symptoms include tingling, irritation and/or swelling of the oropharynx; oedemas of the oral mucosa, itching and burning lips, tongue, palate and oropharynx (Fig.2).

Extra-oral affectation is generally on the face and neck with hives, atopic dermatitis, itching of the ears and a runny nose, oral itching, tearing, periorbital oedema, retractions without respiratory obstruction and sneezing (2).

On certain occasions there may be systematic clinical symptoms like: Nauseas, vomiting, stomach aches and diarrhoea, general eczema, asthma, hives, laryngeal 


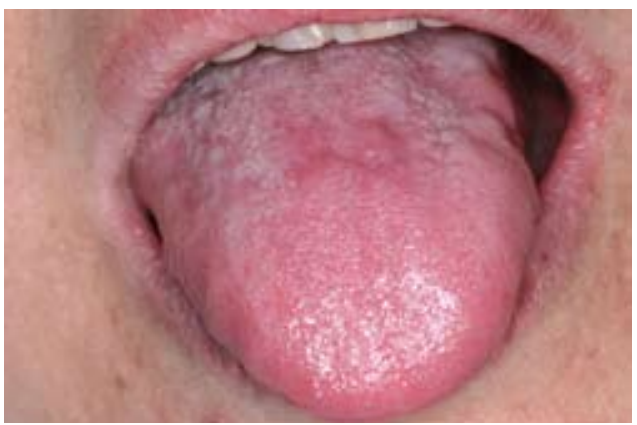

Fig. 2. Asthmatic patient with OAS. Swelling of the tongue and itching after eating a peach.

oedema or even in isolated cases, anaphylactic shock $(10,17,18)$.

OAS may occur during any part of the year, but is often worsened during the season of the pollen instigating it.

Cooked, canned or processed fruits and/or vegetables do not generally unleash the symptoms; this along with the fact that it does not produce symptoms below the oropharynx suggests that the majority of the allergenic proteins are altered by the heat and or digestive processes (1).

\section{Diagnostic data}

A medical history of pollinic allergies and contact with the food provoking them, usually fruit, are the fundamental elements in the clinical diagnosis of this syndrome.

In patients with allergies to air-born particles, the appearance of oral itching or tingling after eating fresh fruit or vegetables is enough to suspect OAS. This is why the medical history must be comprehensive; especially to make sure that it is not a more important allergic problem (1). In patients with allergies to pollen we must ask about the intensity of the symptoms during more active periods, the duration of these allergies in previous years and at what age the pollen-food allergy began. We must also include the type of symptoms that the food triggers, looking to see if they are exclusively around the mouth, in the zone of contact or affecting other distant organs. Finally, it is important to include the time that has passed between the ingestion and the appearance of the symptoms.

An important test in diagnosing food allergies is a controlled double-blind provocation with a placebo, even though it presents multiple problems for OAS. One problem is that the excipient and taste disguise may provoke the loss of the foods' allergenic properties. But the food implicated must be administered naturally, not dehydrated, freeze-dried or in pills, since contact with the oral mucosa is necessary to induce the symptoms (19). Finally, due to the severity of the symptoms in some patients, this test could be potentially dangerous.
The skin tests to determine immediate hypersensitivity will complement the clinical diagnosis of OAS. The skin prick test (SPT) is performed with commercial extracts of pollens and food on the forearm or the back, measuring the 15 minutes, and are considered positive if they are greater than $2 \mathrm{~mm}$ of the negative control sample $(2,20)$. The commercial extracts do not appear as good as when fresh. One of the inconveniences of the skin prick test is the prevalence of false positives and false negatives, and that some of the medications like antihistamines may alter them $(21,22)$.

We must also perform analytical determinations: Complete blood count, total IgE and IgE serum antibodies. The valuation of total IgE allows us to identify atopic patients, without locating a specific allergen (23). IgE serum antibodies can be analysed via radioimmunoassay (RIA), Enzyme-linked immunosorbent assay (ELISA) or chemiluminescence or a radioallergosorbent test (RAST). The RAST test is performed by inhaling pollinic allergens (grass, birch tree...) and food allergens (apple, peach, pear, tomato, potato, carrot, celery, peanut, hazelnut, melon, almond, banana and oranges). Apart from the problems interpreting the results, other inconveniences in these diagnostic tests include their high costs and false positives.

OAS may be confused with other oral pathologies due to the lack of specificity of the current symptom complex. This is why a differential diagnosis must be performed against viral infections (herpetic), recurrent aphthae, erythema multiforme, physical or chemical burns, contact allergies to other substances (toothpaste, odontological material, etc.).

Some serious forms of OAS may present itself as an unspecific ulcer-membranous stomatitis, either as isolated canker sores or in more specific cases with multiple oropharynx affections (23).

As previously noted, in cases of OAS, a history with pollen allergies and contact with food are key.

\section{Treatment and prognosis}

The easiest, safest and cheapest way to treat OAS consists in avoiding fruits and/or vegetables that unleash it $(1,2)$. Since many of the immunogenic proteins in fruits and/or vegetables are unstable (heat-labile), patients will tolerate food cooked and canned well, and fresh or raw foods badly.

Many of the more immunogenic proteins are mainly or exclusively found on the fruit/vegetable's skin, and less so in its flesh, so simply peeling them is not a complete safety measure (2).

In minor, local disorders, simply avoiding repeated contact is enough to resolve the case. If isolated ulcers exists, a topical corticoid may be applied (triamcinolone $0.1 \%$ or fluocinolone $0.05 \%$ ) until resolved.

In disorders established from mediated-IgE with sys- 
temic affection, systemic corticoids should be administered (20).

Due to the possible anaphylactic reaction, epinephrine should be prescribed (via IM injection) and instruct the patient on how to use it if necessary (2). Sometimes antihistamine therapy is recommended for IgE-mediated cutaneous manifestations, but not for systemic reactions (20).

Some studies $(24,25)$ have used immunotherapy against pollens as a treatment to this syndrome, with varying results.

Allergists indicate that a fundamental preventative measure in OAS is informing the patients with pollen allergies about the possibility of developing a hypersensitivity to certain fruits and/or vegetables. So patients aware of which foods provoke their OAS should avoid them or eat them cooked or canned.

The general prognosis of OAS is good, with very few severe reactions. Moreover, approximately one third of patients with food allergies lose their sensitivity after 2 years of strictly not ingesting it (2).

Some authors (2) have concluded that neither the size of the skin test reactions, the total IgE nor the atopical respiratory diseases is sufficient reason to predict severe OAS reactions.

\section{Conclusion}

As a conclusion we can state that oral allergy syndrome (OAS) is an interesting allergy pathology induced by vegetables in sensitive patients, and should be recognised by odontologists. Even though the symptoms are usually minor, some cases may lead to severe consequences. This is why it is important to keep it in mind when diagnosing patients with acute oral symptoms that may be related to the ingestion of fruits and/or vegetables.

\section{References}

1. Nash S, Burks AW. Oral allergy syndrome. Curr Allergy Asthma Rep. 2007;7:1-2.

2. Sloane D, Sheffer A. Oral allergy syndrome. Allergy Asthma Proc. 2001;22:321-5.

3. Liccardi G, D'Amato M, D’Amato G. Oral allergy syndrome after ingestion of salami in a subject with monosensitization to mite allergens. J Allergy Clin Immunol. 1996;98:850-2.

4. Tuft L, Blumstein GI. Studies in food allergy. II. Sensitization to fresh fruits: clinical and experimental observations. J Allergy. 1942;13:574-82.

5. Amlot PL, Kemeny DM, Zachary C, Parkes P, Lessof MH. Oral allergy syndrome (OAS): symptoms of IgE-mediated hypersensitivity to foods. Clin Allergy. 1987;17:33-42.

6. Lázaro M, Cuesta J, Igea J.M. Alergia a rosáceas: el melocotón. Alergol Immunol Clin. 1999;14:234-240.

7. Navarro AM, Orta JC, Sánchez MC, Delgado J, Barber D, Lombardero M. Primary sensitization to Morus alba. Allergy. 1997;52:1144-5.

8. Pastorello EA, Incorvaia C, Pravettoni V, Farioli L, Conti A, Viganò $\mathrm{G}$, et al. New allergens in fruits and vegetables. Allergy. 1998;53:48-51.

9. Cuesta-Herranz J, Lázaro M, Martínez A, Alvarez-Cuesta E,
Figueredo E, Martínez J, et al. A method for quantitation of food biologic activity: results with peach allergen extracts. J Allergy Clin Immunol. 1998;102:275-80.

10. Ortolani C, Pastorello EA, Farioli L, Ispano M, Pravettoni V, Berti C, et al. IgE-mediated allergy from vegetable allergens. Ann Allergy. 1993;71:470-6.

11. Kleine-Tebbe J, Vogel L, Crowell DN, Haustein UF, Vieths S. Severe oral allergy syndrome and anaphylactic reactions caused by a Bet v 1- related PR-10 protein in soybean, SAM22. J Allergy Clin Immunol. 2002;110:797-804.

12. De la Hoz B. Asma Bronquial y alergia a alimentos. Alergol Inmunol Clin. 2001;16 186-194.

13. Lombardero M, Sánchez-Monge R, García Sellés FJ, Barber D, Salcedo G. Purificación y caracterización de dos alergenos homólogos de manzana y melocotón. Homología con LTPs. Rev Esp Alergol Inmunol Clin. 1998;13:252-253.

14. Fernández-Rivas M, Van Ree R, Cuevas M. Allergy to Rosaceae fruits without related pollinosis. J Allergy Clin Immunol. 1997;100:728-33.

15. Blanco C. Síndrome látex-frutas. Allergol Immunopathol. 2002;30:156-63.

16. Salcedo G, Sánchez-Monge R. Proteínas vegetales como panalérgenos alimentarios. Unidad de Bioquímica, Departamento de Biotecnología, E.T.S. Ingenieros Agrónomos, UPM, Madrid. Biojournal.net. Octubre 2005 Available from:http:// www.biojournal. net/pdf/.

17. Ortolani C. Atlas on mechanisms in adverse reaction to food. Introduction. Allergy. 1995;50:5.

18. Ortolani C, Vighi G. Definition of adverse reactions to food. Allergy. 1995;50:8-13.

19. Alonso R, Moncín M, Bartolome B. An alternative food challenge in oral allergy syndrome. J Allergy Clin Immunol. 2004;113:S152.

20. Mansueto P, Montalto G, Pacor ML, Esposito-Pellitteri M, Ditta $\mathrm{V}$, Lo Bianco C, et al. Food allergy in gastroenterologic diseases: Review of literature. World J Gastroenterol. 2006;12:7744-52.

21. David TJ. Adverse reactions and intolerance to foods. Br Med Bull. 2000;56:34-50.

22. Sicherer SH. Clinical aspects of gastrointestinal food allergy in childhood. Pediatrics. 2003;111:1609-16.

23. Madrazo de la Garza JA, Exiga EB. Alergia Intestinal en pediatria. Rev Med. 2004; 42:507-517.

24. Asero R. Effects of birch pollen-specific immunotherapy on apple allergy in birch pollen-hypersensitive patients. Clin Exp Allergy. 1998;28:1368-73.

25. Kelso JM, Jones RT, Tellez R, Yunginger JW. Oral allergy syndrome successfully treated with pollen immunotherapy. Ann Allergy Asthma Immunol. 1995;74:391-6. 